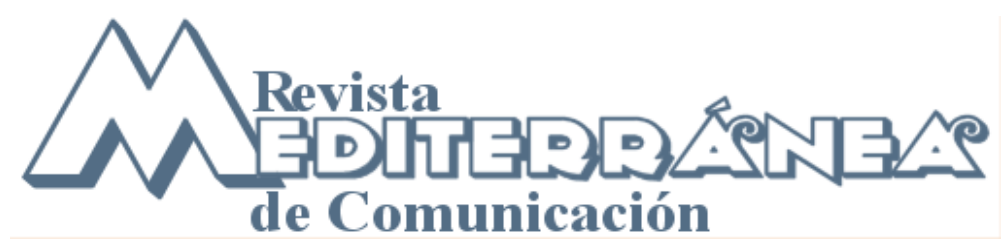

\title{
El peso del contenido publicitario en la prensa alicantina: el caso del Diario Información y La Verdad
}

\section{The role of advertising content in newspapers in Alicante : the case of Diario Información and La Verdad.}

\author{
Alicia de Lara González \\ Profesora de la Universidad Miguel Hernández de Elche (UMH). Spain. \\ a.lara@umh.es
}

\section{Resumen}

La doble crisis que atraviesan los periódicos, la propia del mercado en general y la publicitaria que les afecta más directamente, provoca en el medio impreso una situación contraria a la que cabría esperar: el porcentaje de espacio ocupado por el contenido comercial se mantiene constante. Un comportamiento que sorprende si tenemos en cuenta que la recesión económica obliga a los anunciantes a reducir su gasto en inversión publicitaria. La presente investigación refleja cómo las dos principales cabeceras en la provincia de Alicante, el Diario Información y el periódico La Verdad, recurren a estrategias poco lícitas para contrarrestar la pérdida de inserciones publicitarias, un dato que queda reflejado en la balanza que equilibra el contenido editorial y la mancha publicitaria. El estudio se realiza sobre una muestra comprendida por 1.094 ejemplares, distribuidos de forma equitativa entre ambas cabeceras y entre los años 2007, 2008 y 2009.

\section{Palabras clave}

Investigación; prensa; impreso; publicidad; datos; industria de comunicación; España.

\section{Abstract}

At the moment, the press is facing a double crisis. Both, the general crack and the fall in advertising, which affects it most directly. The lack of adverts is causing in this mass media a situation contrary to what might be expected: the total percentage of space occupied by commercial content remains constant and even rising. This behaviour is surprising when you consider that the economic downturn forced advertisers to reduce their spending on advertising investment. However, as shown in this study, the main newspapers in Alicante: Diario Información and La Verdad, use several strategies, some more profitable than ethical, to counteract the loss of advertising. This is reflected in the scale that balances the editorial content and advertising spots. The study was based on 1.094 newspapers, divided equally between the two media and for the years 2007,2008 y 2009.

\section{Key words}

Research; press; print; advertising; data; communication industry; Spain. 
Sumario 1. Introducción y estado de la cuestión. 2. Metodología. 3. Análisis comparado. 3.1 Evolución de la paginación y de la publicidad. 3.2. Equilibrio entre el contenido publicitario y el editorial. 4. Conclusiones. 5. Bibliografía. 6. Notas

Summary 1. Introduction and state of issue. 2. Methodology. 3. Comparative analysis. 3.1 Evolution of the page and advertising. 3.2. Balance between advertising and editorial content. 4. Conclusions. 5. Bibliography. 6. Notes

\section{Introducción y estado de la cuestión}

La evolución reciente de las inserciones publicitarias en las cabeceras más destacadas de la prensa alicantina apunta a una progresiva disminución de espacios contratados, por otro lado previsible ante la situación de crisis económica mundial. Ello parece coherente con las declaraciones de los medios impresos en general, angustiados por esa reducción del sustento económico de su actividad. Paradójicamente, el soporte - de la publicidad- es el que necesita imperiosamente ser soportado (económicamente) por ella, como sucede también en buena medida en el caso de la radio o de la televisión. La situación es grave ya que, "durante décadas, la publicidad ha sido el motor que generaba los ingresos y no la venta del producto" (Farias y Roses, 2009: 17). Aunque todo esto no resulta nuevo, sí que nos invita a reflexionar ahora sobre los apuros por los que pasa el compromiso informativo de los medios y su dependencia del mercado, apoyándonos en variables que apunten la existencia o no de un equilibrio saludable entre los dos tipos de contenidos que conforman el diario.

El propósito principal del presente trabajo consiste en analizar la compleja relación existente entre el contenido publicitario y el editorial en el diario impreso local. Consideramos que en el contexto actual que pone en tela de juicio la supervivencia de la prensa, resulta importante llevar a cabo una investigación sobre la publicidad que -valga el juego de palabras- soporta al soporte. Como apuntan de Bustos y Casado del Río, "los diarios no han sido rentables en sus inicios, ni lo son ahora. En la actualidad, influye la crisis, que hace descender las inversiones en publicidad, lo cual dificulta aún más las cosas" (De Bustos y Casado del Río, 2010: 4).

En esta ocasión, el análisis publicitario se ha centrado en el diario provincial porque consideramos que el éxito periodístico de este tipo de medios se fundamenta en el interés por parte de la sociedad por conocer aquello que tiene lugar en su entorno geográfico más cercano. En términos de calidad la prensa local debe aspirar a los mismos requisitos que la nacional, pero abarcando su propio ámbito, al que le interesa enfocar por completo sus esfuerzos informativos y comerciales. La publicidad nacional que predomina en las páginas del diario local suele provenir del grupo multimedia al que pertenece el diario regional, pero no es una publicidad que nazca de las virtudes del propio periódico. Por ello, consideramos que, en términos de medios locales, el líder será aquel que acapare a los anunciantes de su ámbito.

Así mismo, los obstáculos competitivos que ha de sortear un medio regional para poder subsistir no son pocos. "Para poder competir con los medios estatales, los periódicos provinciales, incluso los más consolidados, se han visto obligados a integrarse en grupos mediáticos nacionales, regionales o provinciales, cada vez más poderosos" (Fernández Fernández, 2000: 211). Pero no solo ha resultado un impedimento la presencia de los medios estatales, sino también la proliferación de otros muchos medios locales que ha agudizado fuertemente la constante pugna por hacerse con el lector local y con los anunciantes: "The role of the local paper is continually contested and changing. Facing competition from other media, local newspaper circulation has been in steep decline since the late 1980s. This decline has been particularly marked for evening newspapers and paid-for weeklies. Despite the fall in circulation, local newspapers remain 
profitable as advertising revenues continue to soar. In 2002, for example, advertising revenues in the regional press outperformed those of national newspapers, at $£ 2.870$ million" (Wahl, 2005: 81).

Los medios impresos de proximidad se han visto obligados a trazar estrategias comerciales que les permitan subsistir. Algunas de ellas imitan a sus homólogos nacionales, como la proliferación sin freno de las promociones que acompañan al diario. Otras resultan más propias del entramado local, como los publirreportajes institucionales o los especiales comerciales. De esta manera, constatamos que para analizar el contenido publicitario del diario, no basta con contabilizar los módulos comerciales. Por el contrario, con objeto de medir el volumen real de publicidad que alberga el medio, hay que analizarla en sus muy diferentes formas. Es decir, al espacio ocupado por las inserciones convencionales habrá que sumarle el conjunto de la publicidad below the line y la propia o autorreferente en sus diversas maneras de presentación. Solo así será posible obtener una visión realista del porcentaje de espacio que ocupan los contenidos comerciales en el diario y cómo estos han ido ganando terreno a la información en su sentido más estricto. Como argumenta Montero, "medir la intensidad y el valor de la mancha publicitaria se complica cuando entendemos por mancha publicitaria toda aquella comunicación capaz de poner en contacto una marca con su consumidor" (Montero, 2007).

Por todo ello, en el trabajo se han tenido en cuenta, además del muestreo de las inserciones convencionales y los mensajes autopublicitarios, aquellos contenidos híbridos que combinan información y publicidad, comúnmente conocidos como 'publirreportajes'. Consideramos que este tipo de fórmulas aplicadas al medio impreso permiten evaluar el conjunto de publicidad no convencional sobre el que las investigaciones generalistas quedan algo diluidas, debido a su dificultad de estudio y análisis. De acuerdo con Bigné, "en los soportes no convencionales (below the line), tanto la metodología de recogida de información como la clasificación utilizada, dista del rigor y utilidad de la información aportada por los medios convencionales" (Bigné, 2000: 14). Por su parte, Madinaveitia se refiere al grupo de los medios no convencionales como "una mezcla heterogénea de actuaciones (mailing, buzoneo, marketing telefónico, ferias, etcétera), todas ellas muy difíciles de medir con rigor y que InfoAdex se limita a estimar en función de las declaraciones de las asociaciones profesionales correspondientes" (Madinaveitia, 2004: 404).

En este sentido, es necesario subrayar que la comunicación institucional pagada, pero presentada en forma de noticia ampliada, ha ganado un importante espacio en el medio impreso, hasta percibirse, en ocasiones, como una sección más del diario. Como señala Hernández Martínez, "la omnipresencia de las relaciones públicas en los mensajes que recibimos cotidianamente se ha refinado en particular en un tipo de relaciones de prensa, hasta ahora inéditas, en las que una institución y un medio de información tradicional se asocian para generar productos que vehiculan y avalan los propósitos del otro" (Hernández Ramírez, 2006: 193). La autora añade también que los profesionales de las relaciones públicas "se han convertido en 'maestros' en el arte de la hibridación de mensajes públicos, apoyándose en las prácticas desarrolladas por los otros productores profesionales de la comunicación pública (periodistas y publicistas)". No en vano cabe recordar que las relaciones públicas constituyen un "ámbito de investigación y desarrollo creciente pese a las dificultades provenientes del choque con otras áreas afines, como las propias de la comunicación comercial o las relaciones informativas" (Hernández Martínez, 2007: 7).

El otro punto importante en el análisis comercial del diario es el de los contenidos autorreferentes, es decir, los mensajes promocionales que genera e inserta el propio diario en sus páginas. Hemos considerado oportuno registrar detalladamente el espacio generado por el conjunto de mensajes que remiten al propio medio y a los otros medios y empresas que pertenecen al mismo grupo empresarial, ya que también constituyen un contenido comercial. Profundizar en el uso y, en 
ocasiones, abuso, de este tipo de mensajes nos ofrecerá interesantes conclusiones sobre algunas estrategias utilizadas por los diarios para afrontar los contratiempos del mercado mediático.

Conviene recordar que la proliferación de este tipo de formatos comerciales que escapan a la inserción convencional coincide con los datos sobre la inversión publicitaria en España en términos generales: el porcentaje que obtuvieron los Medios Convencionales en 2009 sobre el total de mercado fue del 44,3\%, mientras que los denominados Medios No Convencionales representaron el 55,7\% de la inversión (InfoAdex 2010).

\section{Metodología}

El estudio se centra en los dos periódicos provinciales de pago y no deportivos con mayor difusión en la provincia de Alicante: el Diario Información y La Verdad. La metodología utilizada consiste en la suma del área ocupada por el contenido comercial, con el objetivo de estudiar la relación existente entre la mancha publicitaria y el espacio editorial.

La muestra sobre la que se ha llevado a cabo el trabajo de campo consta de un total de 1.094 ejemplares, repartidos a partes iguales entre ambas cabeceras y durante los años 2007, 2008 y 2009. Al disponer de una medida estándar con la que llevar a cabo el muestreo, el módulo, estamos en disposición de clasificar el espacio total que los ejemplares dedican a uno u otro tipo de contenido y establecer porcentajes respecto al volumen total. En ambos diarios se observa la misma proporción modular de 5×10, es decir, 50 módulos por página.

La suma de módulos y las operaciones matemáticas pertinentes han sido posibles gracias a una base de datos informática confeccionada con el único objetivo de servir al presente estudio. Las ventajas que ofrece la informática a la investigación periodística se mueven, por lo tanto, en el aspecto de las operaciones estadísticas, pero también en el manejo de un material abundante, hasta el punto de que, en la actualidad, no se concebiría una investigación similar a la aquí planteada que no empleara algún tipo de programa informático. Sirva para ilustrar lo dicho que el total de anuncios aquí muestreados y clasificados asciende a más de 40.000 inserciones.

La selección de la muestra se establece con la meta de obtener una proporción representativa de las tres ediciones que comparten ambos medios: Alicante, Elche y Orihuela-Vega Baja, que se hallan distribuidas de forma correlativa con la siguiente selección de días, también correlativa: lunes, miércoles, viernes, domingo, martes, jueves, sábado; desde el 1 de diciembre de 2007 (empezando por la edición de Alicante), hasta el 30 de enero de 2009 (edición Orihuela-Vega Baja). En este sentido, y en relación al uso de técnicas de investigación para analizar fenómenos sociales, como es el caso de las materias relacionadas con la comunicación, Sierra Bravo apunta que este tipo de estudios aplican, como es el caso, técnicas científicas a problemas de la realidad social "para buscar respuestas a ellos y obtener nuevos conocimientos que se ajusten lo más posible a la realidad" (Sierra Bravo, 2001: 41).

Según los datos sobre prensa diaria de pago no deportiva obtenidos del Estudio General de Medios (Acumulado Móvil 3a Ola 2009: Noviembre) se deducen los siguientes porcentajes sobre el total de lectores de prensa local en la provincia: Información: 85\%; La Verdad: 9\%; Las Provincias: 4\% y Otros: 2\%. Respecto al liderazgo del Diario Información en la provincia de Alicante, González Esteban afirma: "Estamos ante un periódico líder que representa una prensa de proximidad potente, influyente y extraordinariamente arraigada" (González Esteban, 2009: 158). Como hemos comprobado, los dos diarios en los que se centra el estudio suman más del el $90 \%$ del total de lectores de la prensa regional de la zona, de manera que las conclusiones que se obtengan serán lo suficientemente representativas del comportamiento publicitario de este sector. 
Es necesario matizar que el trabajo tiene muy en cuenta el contexto actual de las empresas periodísticas, en el que, según el informe de InfoAdex 2010, observamos que la inversión real estimada del mercado experimentó en 2009 un descenso del 14,9\%. Así mismo, también percibimos que, por segundo año consecutivo, todos los medios presentan caídas en su cifra de negocio, con la excepción de internet, cuya inversión crece. Es decir, en el caso concreto de los diarios, la inversión publicitaria obtenida en 2009 está un 22,1\% por debajo de la cifra del año anterior, que fue de 1.507,9 millones, mientras que, como apuntábamos, los medios no convencionales presentan resultados mucho más saludables, a pesar del envite de la crisis. Las cifras no dejan lugar a dudas sobre la recesión que atraviesa el entramado mediático, la cual se está cebando especialmente con el potencial de la inversión publicitaria.

Así mismo, el análisis de contenido está apoyado con entrevistas a los responsables del departamento comercial y de marketing de los dos periódicos analizados.

Como dejábamos entrever, "resulta lógico pensar que si el número total de páginas desciende debido a la crisis económica que atraviesa el sector y a que el papel constituye un importante coste en el proceso de producción, los diferentes contenidos que pueblan el diario deberán decrecer de forma proporcional a tal descenso" (De Lara, 2010: 132-152). Intuimos que, a pesar de la recesión económica, el descenso de pliegos ha afectado más al porcentaje de contenido informativo y no tanto al espacio dedicado a la publicidad.

Como hipótesis de partida aventuramos que algunas de las estrategias planteadas por los periódicos impresos para hacer frente a las penurias económicas y a la necesidad de cuadrar ediciones consisten, precisamente, en otorgar mayor protagonismo al contenido sobre el que ejercen total control y que les genera menor coste: los publirreportajes y los contenidos autopublicitarios. Se trata a su vez de una forma de contrarrestar, a ojos del lector, tanto la pérdida de inserciones pagadas como el descenso de información publicada.

\section{Análisis comparado}

Como señalábamos, en palabras de Farias y Roses, "los propietarios de los medios de comunicación han pretendido combatir la crisis con estrategias como las reducciones de plantilla, la disminución de las tiradas, la adaptación a nuevos formatos, la incorporación de todo tipo de promociones, las transiciones del pago a la gratuidad, las concentraciones de empresas para reducir costes, etcétera" (Farias y Roses, 2009: 16). A continuación se reflejan algunas de estas estrategias, concretamente aquellas que afectan más directamente al resultado del ejemplar y al equilibrio entre los dos ingredientes básicos que lo conforman: la información y la publicidad.

Para analizar la evolución del protagonismo que adquiere uno u otro contenido no basta con contabilizar el total de módulos según el año. Por el contrario, es necesario situar los datos en contexto, ya que la variable del total de páginas también interfiere en el porcentaje global de espacio ocupado tanto por la publicidad, como por el contenido editorial. 


\subsection{Evolución de la paginación y de la publicidad}

\section{Gráfico 1. Evolución total de páginas 2007-2009, Diario Información y La Verdad}
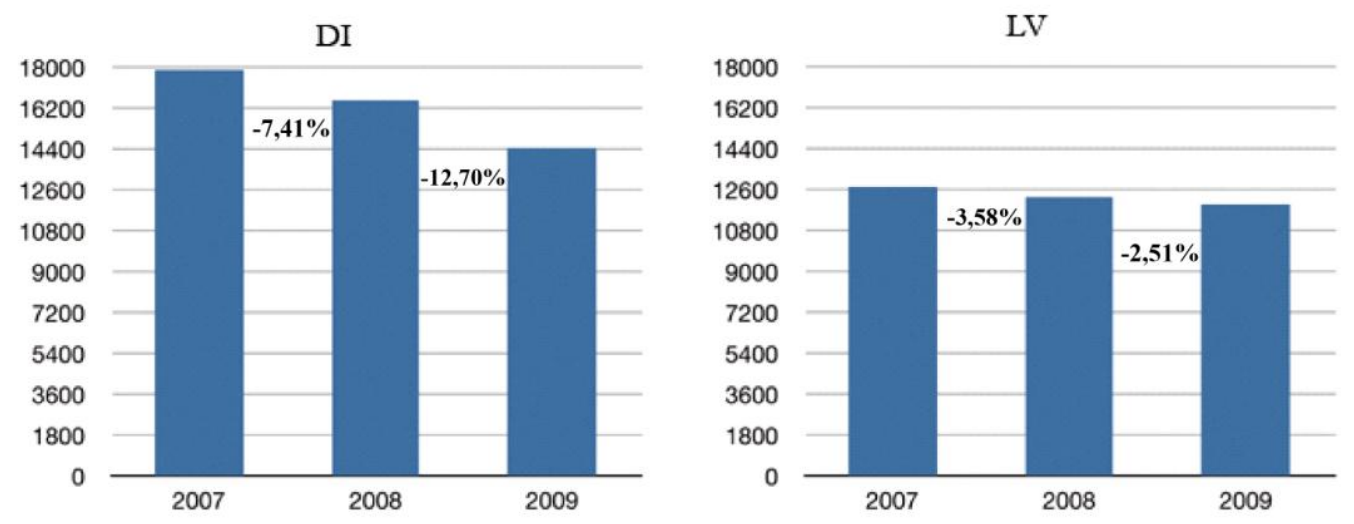

Gráfico 2. Evolución del total de módulos publicitarios 2007-2009, Diario Información y La Verdad
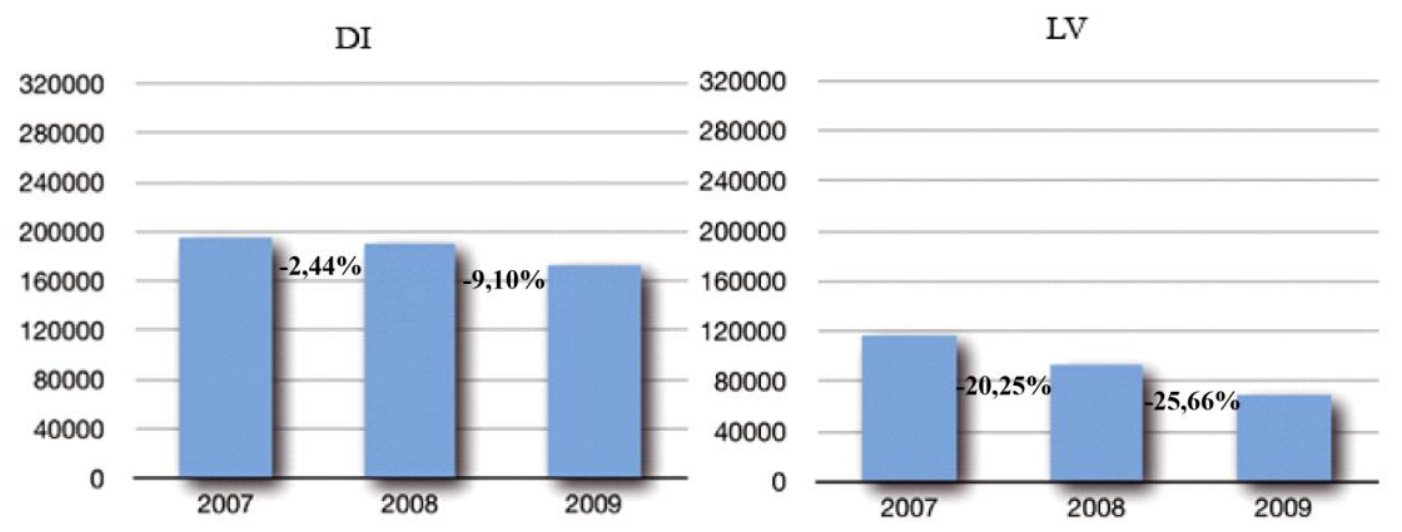

Los gráficos sobre módulos publicitarios muestran exclusivamente el espacio ocupado por las inserciones convencionales, es decir, la contratación modular según tarifa, ya que el comportamiento del resto de contenido comercial fuera de esta definición quedará reflejado en el apartado siguiente.

En primer lugar, en el gráfico 1 observamos que la evolución de la paginación y de la publicidad de las cabeceras es en ambos casos decreciente. No obstante, mientras el diario La Verdad ha mantenido prácticamente estable su volumen de páginas y presenta un acusado descenso del contenido publicitario a lo largo de los tres años estudiados (un descenso acumulado de más del $40 \%$ ), el Diario Información, por su parte, aunque ha preservado el espacio total dedicado a las inserciones, ha experimentado una reducción muy significativa en lo que a páginas se refiere (casi del 20\%).

Por su parte, La Verdad muestra un importante descenso de módulos publicitarios (más del 40\% de descenso acumulado), mientras que la reducción de páginas no es muy acusada (6\%). De esta manera, deducimos que el recorte de papel ha afectado principalmente al contenido comercial, que es el que ha sufrido una notable caída y que, por el contrario, la proporción de espacio que se le concede al contenido editorial se ha mantenido intacta. Este dato fue contrastado en su 
momento por la directora de Control de Gestión de la cabecera, Mํㅡ Carmen Valentín ${ }^{1}$, quien apuntó que, efectivamente, el diario se había visto obligado a reducir el papel para disminuir los costes, pero que las páginas dedicadas al contenido informativo se habían respetado. Si las páginas descienden de forma leve, mientras que el contenido publicitario lo hace de forma acusada, resulta lógico concluir que el espacio que se sacrifica es el dedicado al contenido publicitario, y no el informativo. Este dato puede resultar beneficioso en términos editoriales, ya que implica que el contenido estrictamente informativo ha mantenido sus proporciones, pero desde el punto de vista económico, la reducción tan brusca de espacio publicitario conlleva consecuencias muy negativas respecto a la rentabilidad. Además, si atendemos de nuevo a los porcentajes y nos apoyamos en el conocimiento del mercado de la comunicación, deducimos que la reducción de páginas dedicadas al contenido comercial no proviene de una decisión empresarial, sino que más bien responde a la única alternativa posible ante la falta de contratación de espacio.

Por otra parte, conviene ahora centrar nuestra atención en el Diario Información para también determinar qué tipo de contenido, publicitario o editorial, se ha visto perjudicado por la reducción de papel. Se trata de un dato de especial calado teniendo en cuenta que el descenso de paginación es mucho más acusado en este medio.

De esta manera, observamos que el declive de espacio publicitario más notable en el Diario Información tiene lugar en el último tramo del estudio, es decir, durante el año 2009 (descenso del 9\%), ya que la evolución entre 2007 y 2008 se mantiene prácticamente constante. No obstante, también constatamos que esta reducción de espacio dedicado a la publicidad, experimentado en el último año, no coincide en proporción con el descenso de páginas, variable que se muestra más acusada (descenso de casi el 13\% entre los años 2008 y 2009). Es decir, al contrario de lo que sucedía en el diario La Verdad, en el caso del Diario Información todo apunta a que el contenido que se ha visto más perjudicado es el estrictamente informativo, ya que existe una reducción de páginas notable, pero el descenso de contenido publicitario es mínimo. Lógicamente, y por descarte, se intuye que el diario ha prescindido de páginas con contenido editorial, respetando más las dedicadas a la publicidad. Al disminuir en páginas mucho más de lo que disminuye en espacio comercial, se concluye que en este medio existe una tendencia a una creciente "densidad" publicitaria y a una decreciente "densidad" informativa.

\subsection{Equilibrio entre el contenido publicitario y editorial}

Una vez analizado el comportamiento de las inserciones convencionales y la paginación conviene ahora completar la información recabada con los datos sobre el resto de contenidos comerciales más relacionados con las acciones de marketing y el mundo de las relaciones públicas, aunque con un cariz algo desvirtuado en ambos casos. A lo largo del estudio hemos podido comprobar cómo las promociones de producto que acompañan al diario han dejado de ser algo puntual para convertirse en un complemento diario del ejemplar. Se trata de una fórmula que nace como una herramienta de aplicación esporádica, que ha devenido en una estrategia empleada de forma intermitente, y para obtener beneficios a corto plazo.

Por otra parte, el trabajo de campo también ha dado luz al diverso abanico de contenidos híbridos que combinan información y publicidad. Se trata de mensajes que en la mayoría de los casos carecen de la debida identificación publicitaria, pero tras los cuales sí existe un pago, que es el que determina su aparición, por encima del carácter noticioso del mensaje

A continuación, observamos representados los porcentajes existentes entre el contenido publicitario y el informativo o editorial de cada diario, con el objetivo de determinar si existe un equilibrio entre ambos. En este sentido, conviene tener en cuenta que "los medios impresos 
diarios suelen insertar alrededor del $30 \%$ de publicidad y las revistas pueden llegar hasta el $50 \%$ " (Manfredi, 2004: 192). De lo que se deduce que la proporción adecuada entre ambos contenidos debe oscilar entre el 70 y $30 \%$, información y publicidad, respectivamente. En esta ocasión, a la hora de confeccionar los gráficos sí se ha tenido en cuenta el total del contenido publicitario, tanto convencional como no convencional (textos híbridos informativo-comerciales, autopromoción, patrocinios...), con el objetivo de obtener unos porcentajes lo más próximos posibles a la realidad.

Gráfico 3. Diario Información: porcentajes de contenido informativo y publicitario, 2007-2009

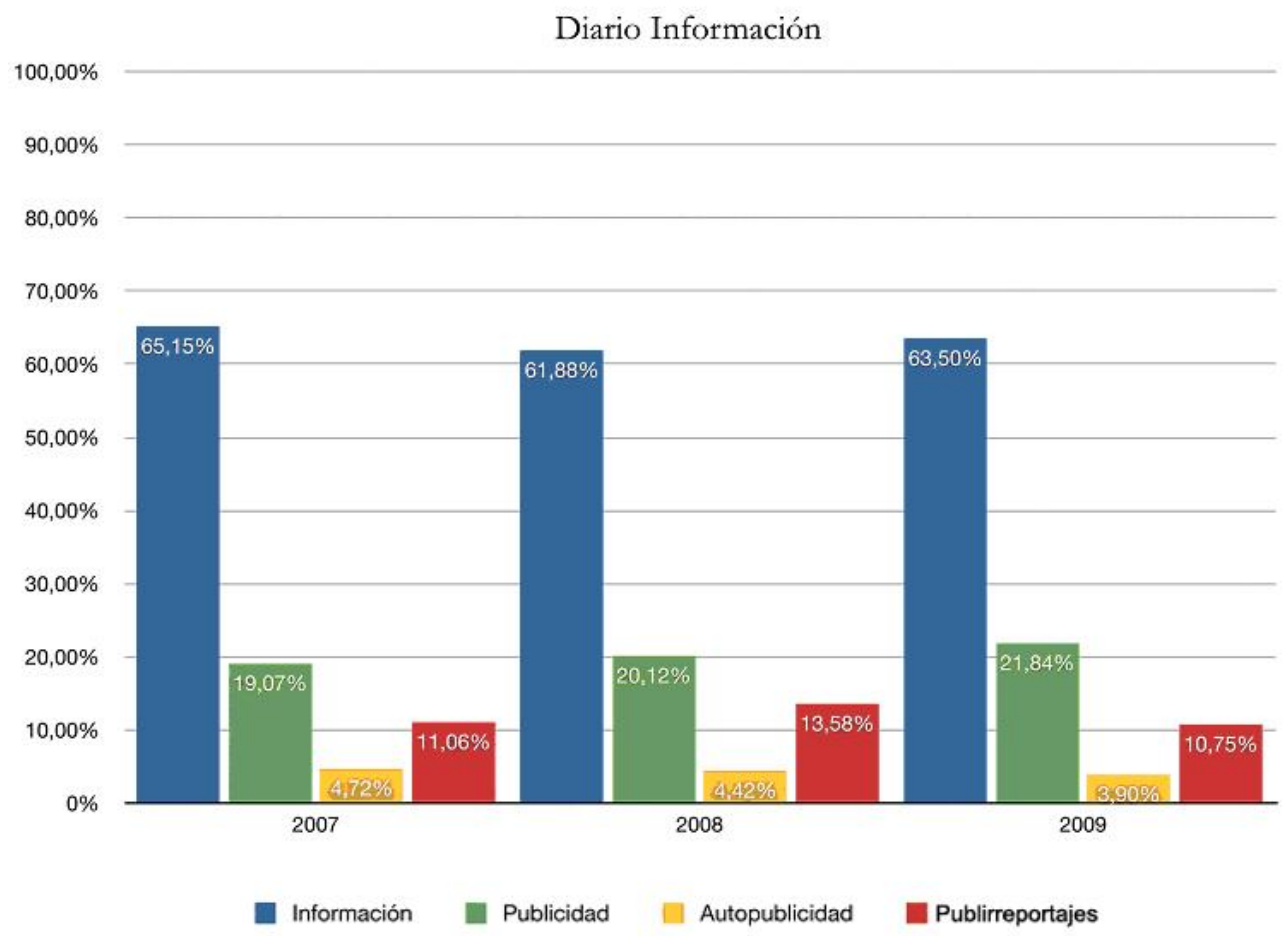


Gráfico 4. La Verdad: porcentajes de contenido informativo y publicitario, 2007-2009

La Verdad

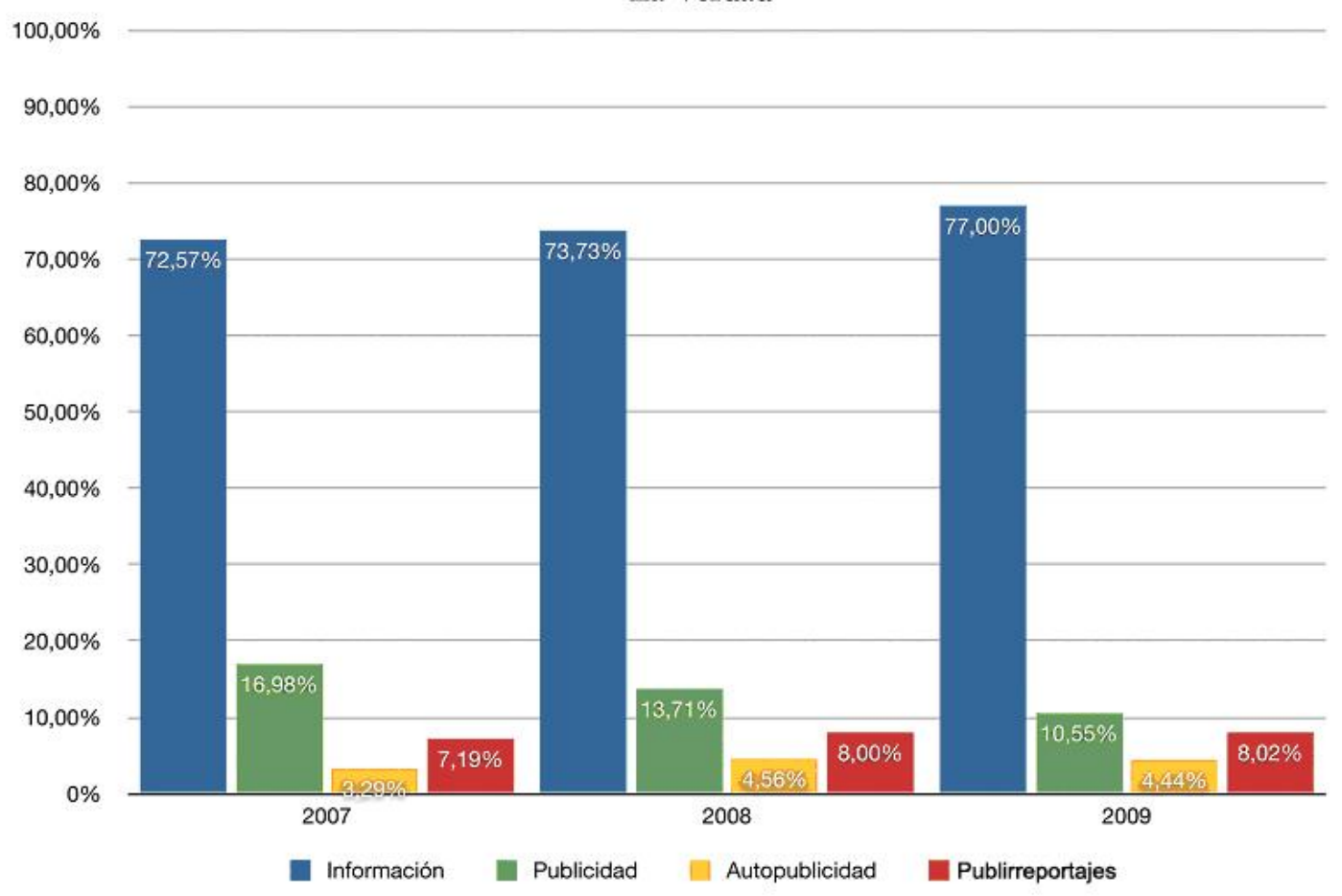

Tabla 1. Diario Información: evolución del equilibrio entre contenido editorial y publicitario 2007-

\begin{tabular}{|l|l|l|l|}
\hline Información & $\mathbf{2 0 0 7}$ & $\mathbf{2 0 0 8}$ & $\mathbf{2 0 0 9}$ \\
\hline Contenido editorial \% & $65,00 \%$ & $61,00 \%$ & $63,00 \%$ \\
\hline Total conten. public. \% & $35,00 \%$ & $39,00 \%$ & $37,00 \%$ \\
\hline
\end{tabular}

Media equilibrio: $63 \%$ contenido editorial y $37 \%$ contenido publicitario.

Tabla 2. La Verdad: equilibrio entre contenido editorial y publicitario 2007-2009

\begin{tabular}{|l|l|l|l|}
\hline La Verdad & $\mathbf{2 0 0 7}$ & $\mathbf{2 0 0 8}$ & $\mathbf{2 0 0 9}$ \\
\hline Contenido editorial \% & $73,00 \%$ & $74,00 \%$ & $77,00 \%$ \\
\hline Total conten. public. \% & $27,00 \%$ & $26,00 \%$ & $23,00 \%$ \\
\hline
\end{tabular}

Media equilibrio: $75 \%$ contenido editorial y $25 \%$ contenido publicitario

A continuación se incluyen también las tablas correspondientes a las cantidades totales de módulos en cada cabecera y su evolución a lo largo de los tres años, con el fin de añadir la perspectiva que ofrecen las cifras reales a la visión porcentual. 


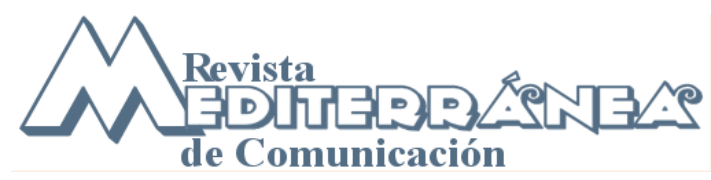

ISSN 1989-872X - Año2 (2011), pp. 59- 71

Tabla 3. Diario Información y La Verdad: total de espacio informativo y comercial según la cantidad de módulos, 2007-2009

\begin{tabular}{|l|l|l|l|}
\hline Información & $\mathbf{2 0 0 7}$ & $\mathbf{2 0 0 8}$ & $\mathbf{2 0 0 9}$ \\
\hline Contenido editorial & 583.215 & 512.928 & 459.467 \\
\hline Total conten. public. & 312.035 & 315.972 & 264.133 \\
\hline La Verdad & 2007 & $\mathbf{2 0 0 8}$ & 2009 \\
\hline Contenido editorial & 462.614 & 453.204 & 461.396 \\
\hline Total conten. public. & 175.036 & 161.446 & 137.854 \\
\hline
\end{tabular}

Tras estudiar los datos, comprobamos que de las dos cabeceras de nuestro estudio, el Diario Información presenta (teniendo como referente la proporción $70 \%$ información - 30\% publicidad), un desequilibrio notable en favor del contenido publicitario: $63 \%$ contenido editorial y $37 \%$ contenido publicitario. Por su parte, La Verdad también lo refleja, pero hacia el otro lado de la balanza, el del contenido editorial: $75 \%$ contenido editorial y $25 \%$ contenido publicitario.

Consideramos oportuno hacer hincapié en los datos reflejados en el Diario Información durante el año 2008, ya que en este período concreto sí se alcanza una proporción publicitaria algo desmesurada de casi 10 puntos porcentuales por encima de los márgenes establecidos como adecuados. El responsable de Marketing de esta cabecera, Miguel Llobel ${ }^{2}$, apunta que la proporción de contenidos que muestra su diario es la correcta. En concreto, la estima en 70-30\%, información-publicidad, respectivamente. Achacamos que la falta de coincidencia entre las cifras que propone Llobel y los datos que proporciona nuestro estudio se debe a que el responsable no incluye en el muestreo del espacio publicitario el contenido ocupado por los publirreportajes y mensajes propios, mientras que nosotros sí consideramos oportuno, e incluso necesario, tener en cuenta este tipo de mensajes dentro del rango comercial. Para ello, nos basamos en que su inserción depende principalmente de que exista o no un pago tras el mensaje y no responde a los criterios tradicionales de noticiabilidad. En este mismo año también se aprecia cómo la bajada de contenido informativo parece verse contrarrestada con un ligero aumento de páginas dedicadas a publirreportajes e híbridos especiales (contenido que en este período alcanza una notable presencia en el ejemplar).

Si tenemos en cuenta la evolución del total de páginas, concluimos que en el diario líder las proporciones de contenido publicitario (publicidad convencional, autopublicidad y espacio ocupado por los publirreportajes) han aumentado, a pesar de la reducción de papel. Es decir, se constata la hipótesis planteada: el descenso de pliegos ha afectado a la información y no al espacio dedicado a la publicidad, la cual mantiene su porcentaje de ocupación en el ejemplar prácticamente intacto, a pesar de la recesión económica.

Por otro lado, en el diario La Verdad, donde el volumen de páginas se mantiene más constante, se deduce que el aumento porcentual de espacio dedicado a la información (reflejado en el gráfico 4, donde del $72 \%$ en 2007 asciende al 77\% en 2008), no es tal si se atiende a la cantidad de módulos (aportada en la tabla 3). Se constata que, en realidad, este contenido se ha mantenido prácticamente estable. Es decir, no es que la información haya adquirido más presencia en el ejemplar, sino que han disminuido tanto el espacio publicitario, como las páginas (en menor medida). El total de espacio dedicado al contenido editorial es el mismo que hace tres años. 
En este periódico también cabe destacar el espacio propio de la denominada publicidad below the line que, a diferencia de lo que ocurría en el diario líder, no ha aumentado, pero tampoco presentan un descenso considerable. Por lo tanto, se deduce que los contenidos comerciales no habituales se muestran ajenos a la crisis, que ha afectado mucho más a la contratación de espacios convencionales.

\section{Conclusiones}

Las estrategias para sobrevivir a la pérdida de inserciones convencionales que adopta el medio se basan, como hemos comprobado, en la reducción del número de páginas totales del periódico y el aumento de páginas dedicadas a los contenidos sobre los que el medio posee total autonomía; en la proliferación de publirreportajes de diversos tipos y en el aumento de las distintas formas de publicidad autorreferente. Es obvio que el objetivo que lleva a poner en práctica estas estrategias se halla lejos de perseguir la calidad editorial del medio. De esta manera, en el Diario Información se constata la hipótesis planteada: el descenso de papel ha afectado al contenido editorial y no al espacio dedicado a la publicidad, la cual mantiene su volumen porcentual en el ejemplar prácticamente intacto, a pesar de la recesión económica. Por su parte, en La Verdad, aunque se mantienen los porcentajes de contenido editorial y descienden los de la publicidad convencional, hemos observado que el espacio dedicado a los publirreportajes y a la autopromoción sí se mantiene constante e incluso aumenta un punto porcentual. Algo reseñable, teniendo en cuenta la crisis publicitaria que atraviesa el diario.

Ha quedado patente, por otra parte, que a la hora de medir la magnitud de la mancha publicitaria es prioritario tener en cuenta el conjunto de contenidos comerciales y no solo las inserciones convencionales. Incluirlos o no puede llegar a suponer alrededor de un 10\% del espacio total de diferencia en el ejemplar, una cifra nada despreciable, ni en términos de rentabilidad monetaria, ni en cuanto a equilibrio información-publicidad. Lo expresado queda patente en el diario líder de la provincia de Alicante, aquel que, por sí solo, aglutina a la mayoría de lectores y que, por lo tanto, representa la pauta general del comportamiento de la prensa alicantina.

En cuanto al constatado incremento de los mensajes híbridos que combinan información y publicidad, cuyo objetivo no es otro que ensalzar las bondades de una marca o empresa, coincidimos con López cuando afirma que gran parte de la culpa de la difícil situación que atraviesa la industria periodística del papel la poseen los propios editores, que se han cegado por las cuentas de resultados económicos, olvidando otras importantes premisas del oficio: "Muchos periódicos, canales de televisión y emisoras de radio no son otra cosa que grandes vendedores orientados a convencer a audiencias específicas de la bondad de ciertos automóviles, cosméticos, ropa o incluso políticos" (López, 2004: 22). Y, por último, la proliferación de la publicidad sobre los productos que acompañan al ejemplar refleja la preocupante situación que atraviesa el medio impreso, que busca en la promoción de productos, más o menos ajenos al diario, la tabla de salvación para alcanzar los resultados económicos marcados, sin plantearse seriamente los problemas de saturación y desvirtualización del periódico que a la larga esto puede conllevar.

\section{Bibliografía}

AIMC (2009): Resumen General de Resultados EGM. Acumulado Móvil 3a Ola 2009, Noviembre. Asociación para la investigación de los medios de comunicación (AIMC). Disponible en: 
http://www.aimc.es//-Datos-EGM-Resumen-General-.html Fecha de consulta: 18 de mayo de 2010.

BIGNÉ, E. J. (2000): Temas de investigación de medios publicitarios. Madrid. ESIC.

DE BUSTOS, J. y CASADO DEL RÍO, M. A. (2010): "Sobre pago y gratuidad. Momentos de crisis en la industria periodística". Telos. Número 83. Disponible en: http://sociedadinformacion.fundacion.telefonica.com/DYC/TELOS/REVISTA/DetalleArtculo83 TELOS PERSPECT 1/seccion=1271\&idioma=es ES\&id=2010051709220001\&activo=6.do Fecha de consulta: 15 de julio 2010.

DE LARA, A. (2010): "El problema del autobombo en el diario impreso". Miguel Hernández Communication Journal, 1, 132 a 152. Universidad Miguel Hernández, UMH (ElcheAlicante). Recuperado el 11 de octubre de 2010 de: http://mhci.es/2010/05/30/lara gonzalez/

FARÍAS, B. y ROSES, S. (2009): "La crisis acelera el cambio de negocio informativo". Estudios sobre el mensaje periodístico, 15, 15-32. Disponible en: http://revistas.ucm.es/inf/11341629/articulos/ESMP0909110015A.PDF Fecha de consulta: 15 de octubre 2010.

FERNÁNDEZ FERNÁNDEZ, M. (2010): "De las linotipias a la comunicación digital: los retos del nuevo periodismo local". Historia y Comunicación Social 2000, número 5, 203-218, disponible en: http://revistas.ucm.es/inf/11370734/articulos/HICS0000110203A.PDF Fecha de consulta: 16 de octubre de 2010.

GONZÁLEZ ESTEBAN, J. L. (2009): "Modelos de periodismo local y estrategias ante la crisis: el caso del News \& Observer". Revista Latina de Comunicación Social, 64, 151 a 160. La Laguna (Tenerife): Universidad de La Laguna, recuperado el 4 de marzo de 2010, de http://www.revistalatinacs.org/09/art/14 $81311 \mathrm{MH} / \mathrm{JL}$ Gonzalez Esteban.html

HERNÁNDEZ MARTÍNEZ, S. (2007): "La nueva geografía de las relaciones públicas". Sphera publica 2007. Revista de ciencias sociales y comunicación, 7, 7-14. Disponible en: http://www.ucam.edu/sphera/numeros/numero-7/SPHERA 7.pdf Fecha de consulta: 16 de octubre de 2010.

HERNÁNDEZ RAMÍREZ, M. E. (2006): "Reseña de 'Practiques novatrices en comunication publique. Journalisme, relations publiques et publicité' de Marc-François Bernier, Franç Demers, Alain Lavigne, Charles Moumouni y Thierry Watine". Comunicación y Sociedad, julio-diciembre, 6, 189-195 http://redalyc.uaemex.mx/redalyc/pdf/346/34600610.pdf Fecha de consulta: 16 de abril 2010.

INOFOADEX (2010): Resumen de InfoAdex 2010, disponible en: http://www.infoadex.es/estudios/resumen2010.pdf Fecha de consulta: noviembre 2010.

LÓPEZ, M. (2004): Nuevas competencias para la prensa del siglo XXI. Barcelona. Paidós.

MADINAVEITIA, E. (2004): "El reto de la complejidad". Medios de Comunicación social. Tendencias 
http://www.infoamerica.org/TENDENCIAS/tendencias/tendencias06/pdfs/43.pdf Fecha de consulta: 16 de abril 2010

MANFREDI, J. L. (2004): Manual de Producción Periodística. Alcalá de Guadaira MAD Eduforma.

MONTERO, C. (2007): "La experiencia y los nuevos retos". Resumen estudio de InfoAdex 2007. Disponible en: http://www.infoadex.es/estudios/resumen2007.pdf Fecha de consulta: 10 de octubre 2010.

SIERRA BRAVO, R. (2001): Técnicas de investigación: teoría y ejercicios. Madrid. Paraninfo.

WAHL-JORGENSEN, K. (2005):"The market vs. The right to communicate: the anti-political local press in Britain and the journalism of consensus. The Public Vol. 12, 3, 79-94. Disponible en: http://www.javnost-thepublic.org/media/datoteke/2005-3-wahl.pdf Fecha de consulta: 25 de septiembre de 2010.

\section{Notas}

1. Información recabada a través de una entrevista personal realizada a la directora de Control de Gestión del diario La Verdad, en Murcia, el 15 de septiembre de 2010.

2. Información recabada a través de una entrevista personal realizada al director de Marketing del Diario Información, en Alicante, el 22 de septiembre de 2010. 